\title{
昜Digital Publisher
}

ISSN 2588-0705

\section{COVID 19 factor de cambio en} la conducta del consumidor

\section{COVID 19 factor of change in} consumer behavior

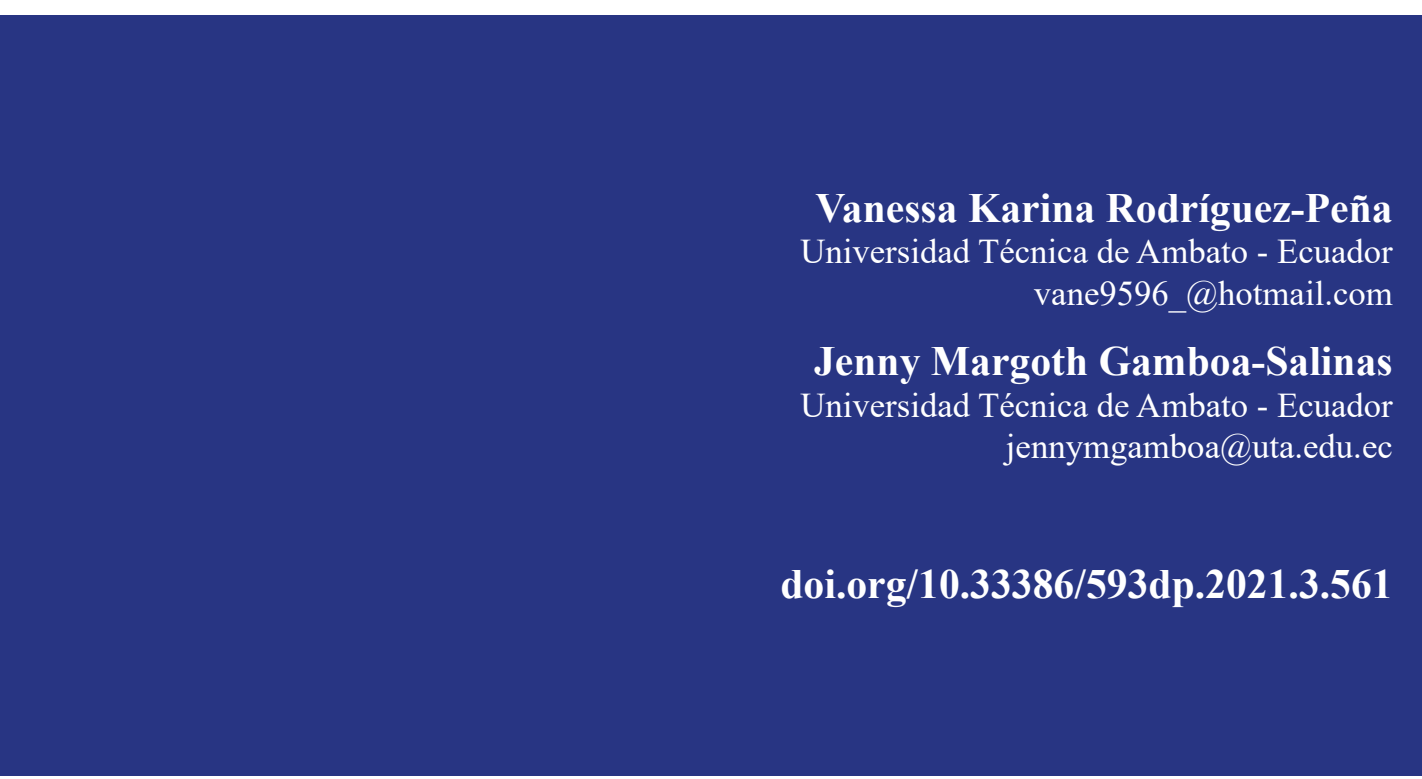

V6-N3 (may-jun) 2021, pp. 188-200 | Recibido: 12 de marzo de 2021 - Aceptado: 14 de abril de 2021 (2 ronda rev.) 


\section{RESUMEN}

La expansión del COVID 19 contrajo efectos comerciales y económicos de magnitud en cuanto a la integración económica mundial, además el nuevo coronavirus ha originado eslabones de disrupciones en la cadena de valor global, reducción en la demanda de ciertos bienes y servicios e incremento de otros, alterando así la dinámica de los mercados. Es importante tener en cuenta que esta pandemia altero psicológicamente la conducta del consumidor, debido al miedo de contagiarse. El objetivo de la presente investigación se basa en caracterizar los cambios en la conducta del consumidor como consecuencia de la pandemia. El método de investigación se realizó de manera cuali-cuantitativo que permitirá la medición numérica, en la primera parte hace referencia a una investigación bibliográfica, y la segunda parte se lo realizo mediante instrumento de investigación realizadas en la provincia de Tungurahua. Mediante los análisis realizados se pudo identificar que el consumidor tuvo que dejar de lado la actividad de compra presencial, a realizarlas mediante el internet, algo que no fue normal pero sin embargo lograron adaptarse debido a un cambio drástico e inesperado, generando así a que la familia será la prioridad en este nuevo consumidor post-coronavirus.

Palabras clave: cambio; conducta; consumidor; COVID 19

Cómo citar este artículo:

APA:

Apellido-Apellido, N., \& ApellidoApellido, N., (2021). COVID 19 factor de cambio en la conducta del consumidor. 593 Digital Publisher CEIT, 6(3), 188-200. https://doi. org/10.33386/593dp.2021.3.561

Descargar para Mendeley y Zotero

\section{ABSTRACT}

The expansion of COVID 19 contracted commercial and economic effects of magnitude in terms of world economic integration, in addition, the new coronavirus has caused links of disruption in the global value chain, reduction in the demand for certain goods and services and an increase in others, thus altering the dynamics of the markets. It is important to bear in mind that this pandemic psychologically altered consumer behavior, due to fear of contagion. The object of research is based on characterizing the changes in consumer behavior as a consequence of the pandemic. The research method was carried out in a quali-quantitative way that will allow numerical measurement, in the first part it refers to a bibliographic investigation, and the second part is carried out by means of a research instrument carried out in the province of Tungurahua. Through the analyzes carried out, it was possible to identify that the consumer had to put aside the in-person purchase activity, to do it through the internet, something that was not normal but nevertheless they managed to adapt due to a drastic and unexpected change, thus generating the family will be the priority in this new post-coronavirus consumer.

Key words: change; conduct; consumer; COVID 19 


\section{Introducción}

La enfermedad COVID 19 (Corona Virus Disease 2019) es el nuevo coronavirus tipo 2 del síndrome respiratorio agudo grave o SARS-CoV2 (severe acute respiratory syndrome coronavirus 2) que afecta directamente al ser humano (IHME, 2021). Los primeros casos se reportaron en Wuhan, China por medio de la Organización Mundial de la Salud (OMS) a finales del mes de diciembre del 2019, esta pandemia tomo un crecimiento acelerado a nivel mundial, el mismo que provocó un aislamiento inesperado para la población con medidas de prevención, seguridad y cuidado de la salud (Organización Mundial de la Salud, 2020). Sin embargo, médicos especialistas que tratan este virus a los pacientes, mencionan que el daño generado por el mismo no solamente es a los pulmones, sino que afecta a todos los órganos y es algo difícil de controlar el estado de los pacientes (Gemelli, 2020).

El bombazo inesperado y generalizado de la pandemia del coronavirus afecta directamente a países con alto nivel de contagios puesto que dependen del comercio internacional, turismo, exportaciones y financiamiento externo, debido al brote de este virus se ven forzados a cerrar dichas actividades (Felsenthal, 2020).

El 16 de marzo en Ecuador, con un total de 58 casos positivos y 2 fallecidos, el gobierno pertinente toma seis medidas emergentes: 1) cerrar servicios públicos a excepción de los de salud, servicios de riesgo y seguridad, 2) apertura de hospitales, tiendas, supermercados, 3) suspensión de las jornadas laborales tanto públicas como privadas, 4) toque de queda para personas y vehículos, 5) suspensión de vuelos nacionales, 6) suspensión del transporte interprovincial. Con estas restricciones se estima que el costo será de un 3,5\% del PIB por mes (Haro, 2020).

\section{El consumidor}

La actuación del consumidor procede del concepto de mercadotecnia que se centra básicamente en las necesidades, el cual para su optimización ha sido relacionado con la logística comercial (Mancheno, 2018). Satisfacer de forma efectiva las necesidades del cliente actual y potencial, conlleva a un estudio exhaustivo en cuanto a sus gustos, preferencias y necesidades. Cabe recalcar que se refiere al conjunto de actividades que lleva a cabo una persona desde que tiene la necesidad hasta la compra y uso del producto. Es así que el consumidor pasa a ser importante en la empresa puesto que por medio de él se podrá identificar las necesidades actuales $\mathrm{y}$ futuras, con una comunicación fluida y a su vez se gana la confianza y fidelización. (FreireLuisa, 2020).

Los enfoques que puede presentarse en el comportamiento del consumidor son:

Enfoque económico: centrado en "hombre económico", orientado en la maximización de su utilidad ya que cuenta con el conocimiento completo de sus necesidades y de los medios disponibles para satisfacerlos.

Enfoque psicológico: en este enfoque el consumidor está determinado por variables psicológicas (Internas, necesidades y deseos), variables externas (Externas, influencia del entorno) y variables económicas. Sin embargo, al considerar que el consumo se da de forma virtual digital herramientas administrativas como merchandising tienden a evolucionar para estar en línea. (Muso Guagchinga, 2020)

Enfoque motivacional: empuja a las personas a la acción puesto que existe una necesidad insatisfecha, en este enfoque MASLOW en su pirámide estableció una jerarquía de necesidades tales como: fisiológicas, de seguridad, sociales, de estimación y de autorrealización (Paredes \& Velasco, 2015).

Durante el siglo XXI se han generado cambios audaces en diferentes áreas del conocimiento, entre ellos los logros en el ámbito tecnológico, que admite el acceso a internet de manera ilimitada desde cualquier parte del mundo. La aparición del internet no ha dejado a un lado los cambios en el ámbito del marketing considerando que el mencionado término siempre presenta la disyuntiva si está o no ligado a la ética (Saá 
M. J., 2016), siendo uno de ellos el desarrollo del denominado e-commerce que trajo consigo modificaciones en los hábitos de compra de los consumidores y por ende en su comportamiento (Sánchez, 2015).

\section{COVID 19 en el comportamiento del consumidor}

Los compradores tienden a evitar contagiarse del virus, es así que las compras las realizaran de una manera rápida y a precios cómodos, siendo así una característica esencial del e-commerce (tienda online). Si bien la demanda por este medio ha mostrado un verdadero despliegue logrando duplicarse a noveles de penetración en tan solo una semana (Casco, 2020).

\section{Figura 1}

Efectos de la pandemia del covid 19 en el comportamiento del consumidor

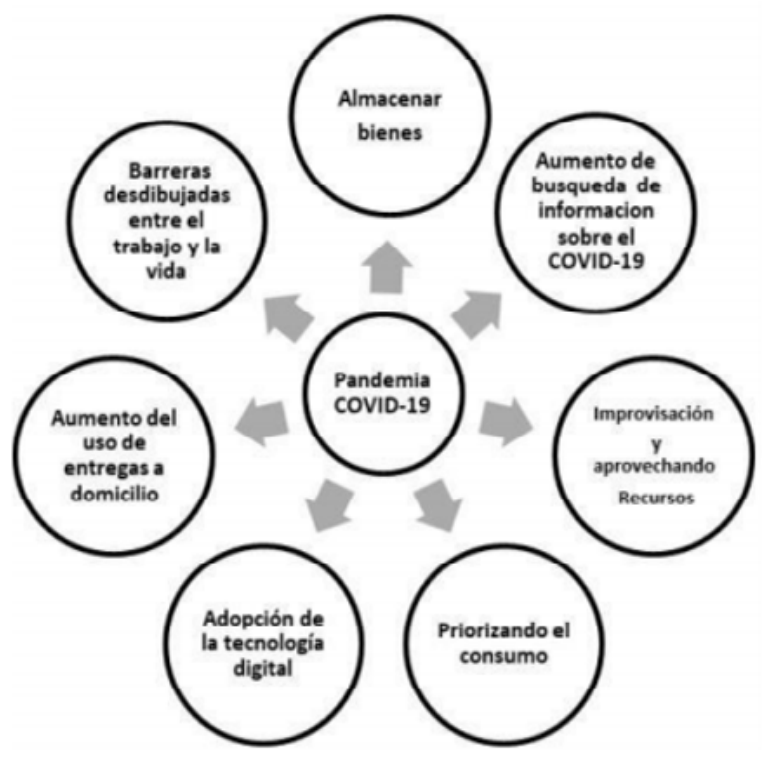

Fuente: (Casco, 2020)

Almacenamiento de bienes: los consumidores están acostumbrados a la disponibilidad de una gran variedad de productos que pueden ser adquiridos en varios minoristas (Laato, Najmul, \& Nazrul , 2020). Sin embargo y debido a la pandemia las personas realizan compras compulsivas siendo generando un cambio en su comportamiento, ya sea por miedo a quedarse sin productos durante el confinamiento o un rebrote.
Aumento de búsqueda de información sobre el COVID-19: al inicio de la pandemia, los consumidores estuvieron sobrecargados de información mediante diferentes paginas en línea con distinta confiabilidad acerca del COVID-19 y sus síntomas (Sheth, 2020). Esto genera a que el consumidor no se enfoque a lo que sucede en su entorno dando como resultado menos autocontrol y realizar compras innecesarias.

Improvisación y aprovechamiento de recursos: la creatividad que se muestra en los consumidores es la confección propia de sus mascarillas de tela, lana o recursos propios con los que cuenta (Wang, An, Gao, Kiprop, \& Geng, 2020). En este sentido los consumidores dan más valor a sus propias creaciones que a las ofertadas en el mercado.

Priorizando el consumo: durante la crisis la tendencia a posponer compras y consumo de servicios innecesarios evitan compras de alto costo, además los objetivos de consumo que se logran a largo plazo solo se dan mediante la negación de los caprichos a corto plazo y al uso ingenioso de los recursos existentes (Mehta, Saxena, \& Purohit, 2020).

Para Kotler (2020), la pandemia ha generado un movimiento anticonsumo que en si busca simplificar la vida, proteger el medio ambiente, fomentar alimentacion sana, liberar el consumismo innesesario del ser humano y cuidar el planeta. La pregunta central es ¿de verdad necesito esto?.

Adopción de nuevas tecnologías: los consumidores por necesidad se han visto en la adaptación de nuevas tecnologías para realizar cualquier actividad como por ejemplo hacer compras en línea, comunicarse con familiares, teletrabajo y participar en eventos virtuales (Sheth, 2020). De esta manera también se incluye la telemedicina, que puede ser tratada por medio de tomografías computarizadas y la endoscopia que puede ser vista por el internet o vía telefónica (Verzaro \& Nishida, 2020).

Aumento de entregas a domicilio: esto debido a las restricciones impuesta en cada nación, los 
consumidores no pueden asistir a las tiendas, centros comerciales (Alon, Farrell, \& Li, 2020). Las empresas que trabajan con las entregas a domicilio han aumentado sus ventas esto con la aparición del COVID-19.

Barreras desdibujadas entre el trabajo y la vida: los consumidores se enfrentaron a la pandemia y sus hogares se convirtieron en aulas de clases, estudios de transmisión, oficinas improvisadas, entre otras cosas, las computadoras como puertas de acceso para interactuar y socializar más allá de los miembros de la familia (Kirk \& Rifkin, 2020).

Asítambiénel factorque afecta el comportamiento del consumidor está relacionado con el psicológico "la felicidad del consumidor", el mismo que es medido a través de la satisfacción de las necesidades psicológicas básicas, los estudios revelan que los consumidores se sienten más felices cuando tienen la mayor prioridad psicológica sobre un producto después del consumo (Li \& Atkinson, 2020)

La aparición del COVID 19, trae consigo elevados costos humanos, económicos y sociales a nivel mundial. Estas secuelas están generando cambios profundos en la economía, estilos de vida, así como en las conductas de compra. De esta manera se debe implementar estrategias empresariales dirigidas a los consumidores adaptada y replantada para este nuevo estilo de vida.

Después de haber concluido el confinamiento, los consumidores volverán de forma progresiva en búsqueda de la normalidad de tal manera que saldrán distantes, preocupados por sí mismos, por su salud. El acudir a las empresas a realizar sus compras será escasa y si lo realizan será con miedo a contagiarse. El consumidor tiende a adaptarse obligatoriamente a canales virtuales para realizar sus compras y pagos de servicios, generando así cambios de escenarios e incertidumbres en el consumidor (López, 2020).

El consumo retoza un papel crítico durante la crisis del COVID 19, forzados a probar cosas nuevas, los grandes cambios estructurales llevan a alteraciones en el comportamiento, forjando limitación del gasto, se le suma la restricción y movilidad por completo, teniendo como resultado a consumidores que saltan al canal digital y ciertas industrias que evidenciaban el proceso antes de la pandemia como la industria relacional a la banca (Llamuca-Pérez, 2019). Cabe recalcar que se estiman diferentes fases hasta volver a la normalidad y esto descartando posibles rebrotes del virus hasta que haya una vacuna, es de esperar estos cambios en el comportamiento sean a largo plazo o incluso permanentes (Asesores Empresariales, 2020).

Con este brote del coronavirus la conducta del consumidor ha cambiado considerablemente al momento de realizar sus actividades diarias de tal forma que obligo a los consumidores a adoptar nuevas costumbres, reevaluar las preferencias y cambiar el consumo, provocando que las empresas se innoven direccionadas al capital intelectual y a satisfacer las demandas inmediatas. (León, 2017). El comportamiento del consumidor consecuentemente tiene cambios, por ende, la flexibilidad y adaptabilidad serán estándares que estarán siempre imprescindibles.

A medida que el COVID 19 se propaga por todo el mundo la vida de los consumidores llegan a ser interrumpida masivamente, el autoaislamiento y bloqueos han cambiado drásticamente el comportamiento del consumidor y cuanto más larga sea esta pandemia, la crisis continua.

Para (Angus, 2020), los cambios de la conducta del consumidor en tiempos de COVID 19 son:

Más allá de lo humano: esto hace referencia a la automatización rápida de operaciones para implementar pedido y entrega sin contacto.

Cautívame en segundos: mantenerse informado durante la incertidumbre se logra mediante contenido rápido, claro, en tiempo real.

Movilidad sin límites: tienden a limitar viajes y si lo realizan lo hacen con cautela y precaución solo en caso de ser necesario viajar.

Inclusivo para todos: priorizando la salud de los consumidores que promocionen recursos 
esenciales para ayudar a las personas de alto riesgo.

Cuidado de mí mismo: tratar el aumento de la angustia y lidiar con el aislamiento en el hogar como la nueva normalidad, que restablecerá el comportamiento y prioridades del consumidor favorece al yo y a la buena salud mental y física.

Hogares multifuncionales: el nuevo centro de vida cotidiana, ya que todas las actividades (trabajo, educación, compras, ejercicio $\mathrm{y}$ socialización, entre otras) pasan a ser virtuales en el hogar.

Personalización privada: utilización de servicios digitales de forma aislada disposición a compartir datos personales en beneficio de la salud pública.

Orgullo local, en camino a ser global: ayuda a pequeñas empresas en busca de productos de origen local.

Revolucionarios de la reutilización: la reutilización de artículos de un solo uso para evitar propagación del virus.

Se idealiza tener un aire limpio en todos lados: suspicacia de la profanación interior durante medidas de confinamiento.

Para los especialistas del marketing enfrentar este cambio en la pandemia es un reto totalmente grande, debido a que se hace uso de la información del consumidor para plantear estrategias y planes de acción (Pumasunco, 2020). Al concebir un cambio fragoso en su comportamiento como no salir de casa no acudir a centros comerciales, bares, escenarios deportivos, paseo de turismo, acudir a cines etc. Es trabajo del mercadólogo identificar el panorama al que se enfrenta el consumidor para plantear nuevas prioridades a las que genera su aislamiento.

Mediante un estudio realizado por la agencia de investigación IPSOS en marzo 2020, expresa que el $60 \%$ de las personas cambiaran su comportamiento de gasto de productos y servicios, una vez culminado la crisis de salud. Se dará prioridad a las áreas de seguro médico con un $56 \%$, el $78 \%$ de los encuestados terminaran consumiendo productos ecuatorianos y como tercer rubro se dará preferencia a paseos y diversión generando prioridad a la familia.

Ante esta situación es importante establecer un marketing de relación debido a que los consumidores buscaran marcas en las cuales poder confiar, las mismas que han estado en las buenas y en las malas mostrando siempre esa conciencia, empatía y creatividad. Cabe destacar que la venta y consumo de productos frescos va en aumento entre las más destacadas se encuentran las frutas, verduras, carnes, huevos y mariscos (Erazo, 2020).

Los hábitos de consumo en las personas durante y después de la pandemia tendrán una repercusión en el mercado de industria digital con un $60 \%$ que se ha vuelto netamente tecnológico, así se referencia la industria de calzado que es una de las más representativas en la zona (Saá M. J., 2016). De tal manera que ha generado menor contacto social que las empresas se ven en la necesidad de realizar publicidad netamente virtual.

La pandemia ha traído un profundo impacto en las compras y en el ritmo de vida del consumidor, de tal manera que la gente se debe adaptar a la tecnología más que nunca para de esta manera respaldar todos los aspectos y consecuencias del aislamiento. Mediante un estudio realizado por Marketing behavior poscornavirus un $61 \%$ de personas planean seguir comprando en línea mientras que un 55\% prioriza el comprar de manera física. Esto quiere decir que se está entrando en un periodo de incertidumbre para los negocios. De tal manera que en este ambiente se debe incluir a las personas de 65 años en adelante, como también a las mujeres embarazadas quienes son más propensas a adquirir el virus y quienes más necesitan de las compras (Donders, y otros, 2020).

La ansiedad y el miedo se es uno de los cambios que se ve reflejado en el consumidor convirtiendo en una preocupación cultural y generacional clave, debido a que el miedo no solo es del bienestar y la salud, sino que a su vez el miedo y preocupación financiera van de la mano debido a que las empresas se ven obligadas a frenar labores, 
dando como resultado pérdida de empleos. Sin embargo, los compradores se vuelven cada vez estrictos en cuanto a los productos que consumen, buscando siempre así la seguridad en los productos o servicios que adquieren. Esto debido a que la manera de contraer el virus es muy fácil mediante las gotitas de respiratoria y a su vez con el contacto directo con la persona infectada (Shi, y otros, 2020).

Más allá de las estrategias de enfatizar y brindar la seguridad a los consumidores también es punto clave el apoyo que tienen departe de las empresas, en tiempo de crisis tanto al empleado y al consumidor, Starbucks es un claro ejemplo en la realización de pedidos digitales, esto genera un contacto mínimo humano y reduce el tiempo en la tienda ya que solo es cuestión de cancelar y retirar el pedido.

Digitalización es otro de los factores de cambio que se ha dado en la pandemia al evitar al coronavirus, de tal manera que buscan servicios digitales afectando a las industrias de comercio minorista, el gobierno ha hecho hincapié en esta situación para gestionar las crecientes demandas de servicios en línea (Edelkoort \& Rodi, 2020).

De tal manera que la presente investigación tiene como objetivo caracterizar los cambios en la conducta del consumidor como consecuencia de la pandemia COVID 19. El mismo que se reflejaran mediante una encuesta realizada a la población que padece de esta cruda realidad.

\section{Método}

La presente investigación está enmarcada en una naturaleza descriptiva a manera de caracterización, donde el diseño ha hecho referencia a un enfoque transversal simple tomando una fotografía del entorno refiriendo está a la conducta del consumidor, se ha generado una muestra la cual fue implementada en la provincia de Tungurahua, donde en el trabajo de campo se refirió a un $52,30 \%$ mujeres y un $47,70 \%$ hombres, de acuerdo con la disponibilidad de un muestreo simple con reemplazo. El segmento por estudiar se enmarca entre los 18- 29 años con un $56,50 \%$.
La investigación es de enfoque cuali-cuantitativo (mixto) que permitirá la medición numérica contrayendo resultados estadísticos, seguido de un estudio retrospectivo en cuanto a la caracterización de los cambios en la conducta del consumidor como consecuencia de la pandemia covid 19.

El instrumento utilizado para la investigación está referido por un cuestionario que se implementó a manera de encuesta digital con Google forms haciendo viral la información a través de un link.

Para el análisis de confiabilidad se utilizó el Alfa de Cronbach implementado en el instrumento para conocer su nivel de confiabilidad, este a su vez va entre 0 a 1 , y si más se acerca al 1 se considera mayormente fiable, la base mínima para aceptar una confiabilidad aceptable es 0.7.

El Alfa de Cronbach refiere una fiabilidad del $70 \%$ donde se ve una interrelación de variables medianamente alta pero válida para la investigación.

\section{Resultados}

Notablemente se dice que los habitantes si tiene conocimientos acerca de las compras por internet, expresado con un $95,30 \%$, es decir que las personas durante el confinamiento si lograron realizar compras online.

Existe un sin número de redes sociales por las cuales se puede realizar el acto de compraventa de productos y servicios entre los más reconocidos: Facebook, Whatsapp, Instagram, Glovo etc. Los mismos que sirvieron para conocer el grado de uso de los habitantes. 


\section{Figura 1}

Red social utilizada para realizar las compras

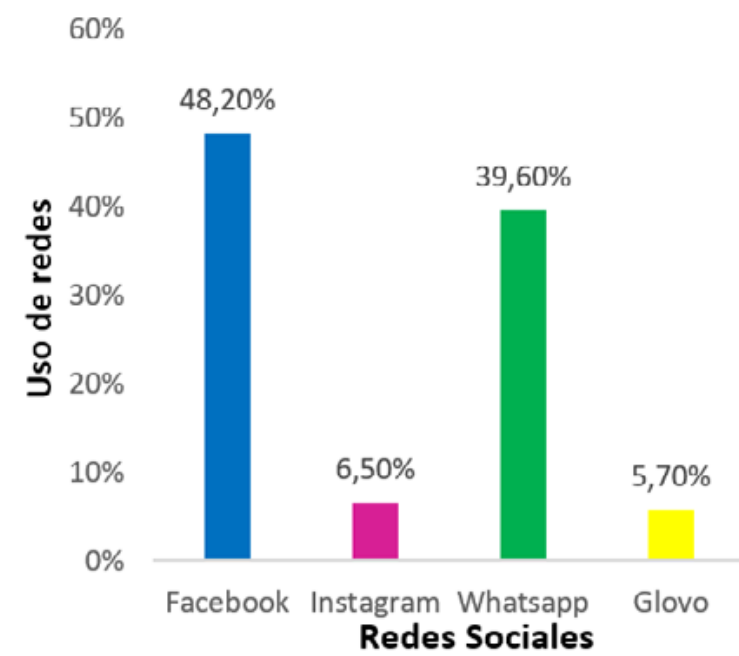

En la figura 1, se muestra la red social que se ha utilizado con mayor frecuencia durante el confinamiento Facebook con el 48,2\%, seguido del Whatsapp con 39,60\%. Estas dos aplicaciones son reconocidas por los usuarios debido a su fácil manipulación y por la gran demanda que tienen las mismas.

Datos estadísticos publicados por Facebook en enero del presente año, mediante la plataforma Statistic Brain Research Institute, el número total de usuarios activos mensuales es de 1.310 millones, y cada día se incrementa más, de tal manera se alude que Facebook ofrece grandes posibilidades para las marcas y empresas, generando así facilidad al usuario a comunicarse, adquirir juegos, compras etc.

\section{Figura 2}

\section{Productos demandados}

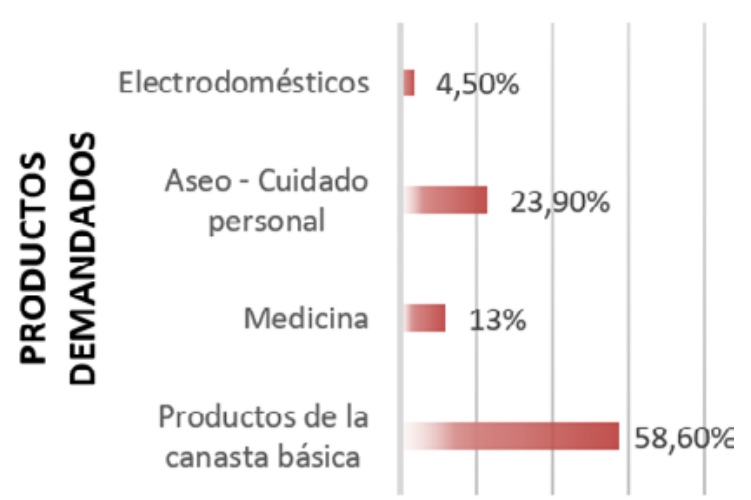

Como se puede observar en la figura 2, los productos básicos fueron los de mayor demanda por la población con el $58,60 \%$, los productos de aseo-cuidado personal con el $23,90 \%$ y la medicina con el 13\%.

Ante los resultados, se puede interpretar que debido al confinamiento y cierre de todo tipo de centros comerciales las individuos tendieron a vender sus productos mediante la web de tal manera que las personas buscaron lo que más se necesitaba para el momento que viene a ser los bienes de la canasta básica (carnes, legumbres, víveres, frutas) como prioridad para la subsistencia propia, así mismo el cuidado que se debía llevar ante el virus llevo a que demanden de productos para el aseo personal (alcohol, shampoo, jabón).

\section{Figura 3}

Importancia de las compras por internet

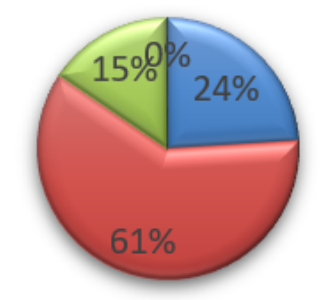

\section{Muy importante $\mathbf{\Delta}$ Importante \\ $\square$ Poco importante $\mathbf{\square}$ Nada importante}

Como muestra en la figura 3, la población con el $61 \%$ considera importante las compras por la web, haciendo referencia a 232 encuestas, un $24 \%$ muy importante y el $15 \%$ poco importante.

Entonces consideran importante las compras por internet, debido a que durante la cuarentena ha sido una herramienta utilizada con frecuencia, generado grandes éxitos en el área de E-commerce, por lo tanto, han considerado que este medio fue efectivo puesto que el miedo al contagio impulso a no salir. 


\section{Figura 4}

Estado personal al momento de la compra por la web

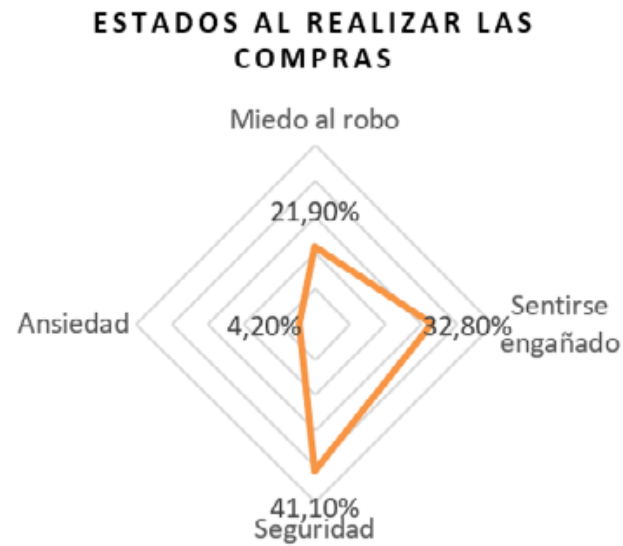

La figura 4, muestra los estados personales al momento de realizar las compras por la web con el $40,10 \%$ han sentido seguridad, seguido de un $32,80 \%$ han sentido ser engañados y un $21,90 \%$ miedo al robo.

Es decir, 158 personas indicaron que al momento de realizar las compras se sintieron seguros esto a que ya tenían conocimientos previos acerca de las compras por internet y que a su vez les fue útil, también el sentirse engañado o miedo a la estafa es uno de los temores que tiene la población esto se debe a que en el mundo si existen las actividades delictivas como clonación de tarjetas, venta de datos personales, duplicación de trasferencias bancarias etc. Es así como las empresas se enfrentan a grandes retos como es ganarse la confianza y lealtad de los consumidores.

\section{Figura 5}

Medio de cancelación de la compra

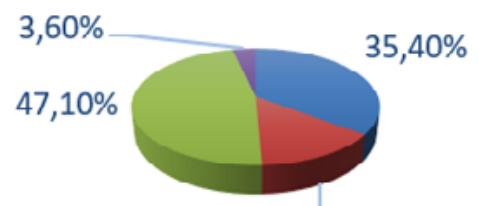

$13,90 \%$

$$
\begin{aligned}
& \text { - Transacción } \\
& \text { - Deposito } \\
& \text { — Efectivo } \\
& \text { — Tarjetas (crédito/debito) }
\end{aligned}
$$

Como muestra en la figura 5, el medio de cancelación más usado por las personas durante el confinamiento con el $47,10 \%$ los realizo en efectivo, con el 35,40\% transacción y el 13,90\% por depósito bancario.

Se alude que las personas para mayor seguridad usaron el efectivo para realizar sus compras mediante la web. Así como también ya después que terminaron con su efectivo acudieron a las transacciones bancarias que como si bien es entendido mayor parte de la población cuenta con una cuenta bancaria.

\section{Figura 6}

\section{Frecuencia de compra por internet}

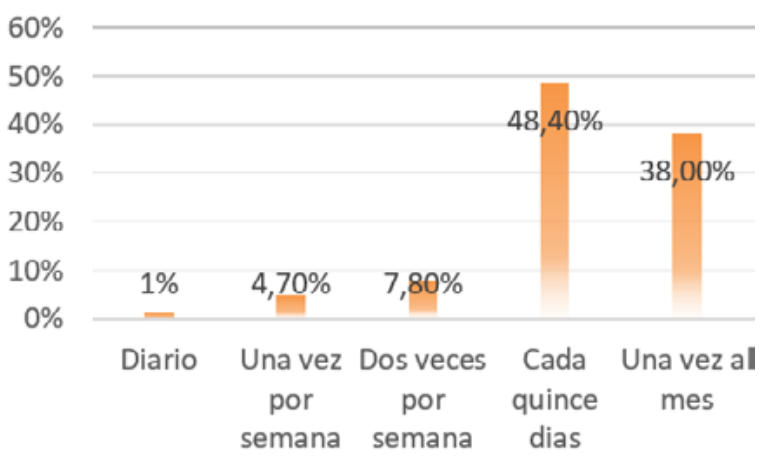

La figura 6, muestra las veces de compra que realiza por internet, con un $48,40 \%$ las personas compran cada quince días, con el $38 \%$ una vez al mes, estas dos variables son las más frecuentes en la población.

Las compras cada 15 días se lo realizada en base a los productos que los adquiere es decir que los productos de la canasta básica los compra en gran cantidad para realizar otra compra dentro de quince días, y las de una vez al mes son las medicinas y los productos de aseo personal de la misma manera se abastecen de lo necesario para el mes es a que son productos no perecibles. 


\section{Figura 7}

COVID 19 como agente de fuerza ante compra por la web

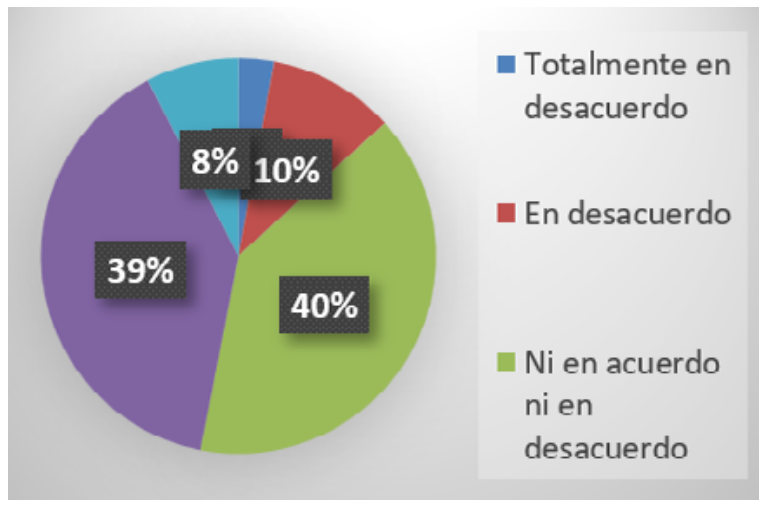

La figura 7 muestra los porcentajes como calificaron las personas a que si el covid 19 forzó a que realicen compras por la web, un $40 \%$ menciono que están ni en acuerdo ni en desacuerdo, seguido de una no significante diferencia de 39\% que califican en estar de acuerdo y un $10 \%$ que están en desacuerdo.

Estos resultados dan a conocer que las personas están, ni en acuerdo, ni en desacuerdo en el contexto que el covid 19 forzó a las compras por la web, esto se debe a que las personas ya tenían conocimiento y en que en cualquier momento de la vida esto iba a suceder que la tecnología ha avanzado a gran escala y que el comprar por la web será ya una forma más de compra con seguridad y confianza.

\section{Figura 8}

Nivel de satisfacción ante la compra por internet

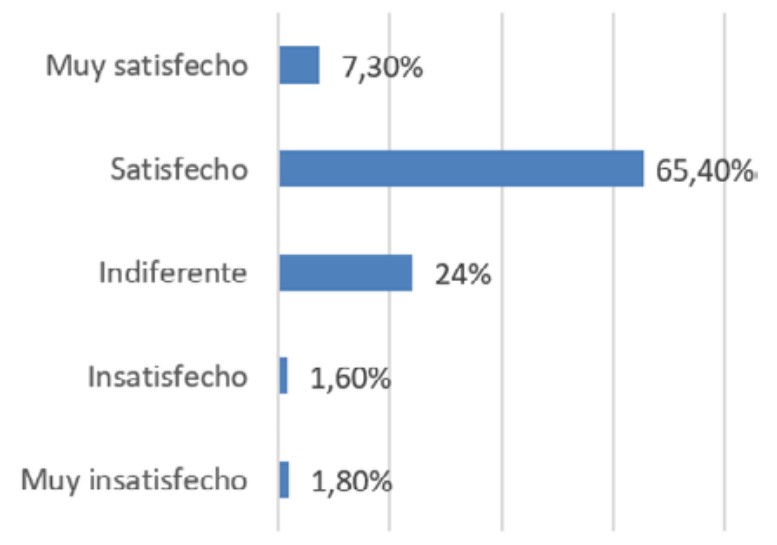

La figura 8 muestra el nivel de satisfacción de la población ante las compras por la web, el $65,4 \%$ se sintieron satisfechos y un $24 \%$ indiferente.

Con estos resultados se considera que la mayor parte de las personas se sintieron satisfechas, con esto se alude que no es ya casi importante ver y observar el producto de manera fisica $y$ más aún ante una pandemia que por el hecho de cuidar su salud se sintieron a gusto en adquirir el producto ya que la situación lo amerita.

\section{Figura 9}

Recomendación de las compras por internet

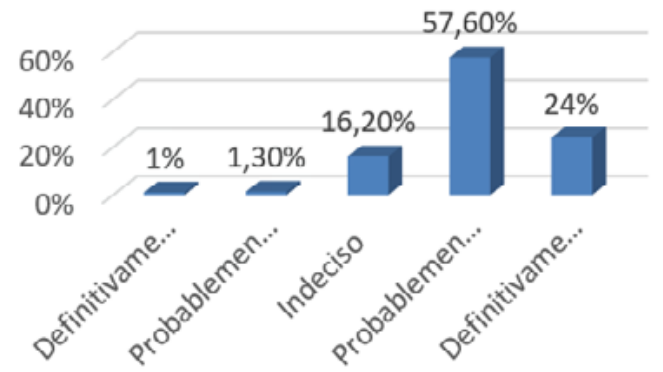

Como muestra la figura 9, el 57,60\% de la población encuestada probablemente recomendaría las compras por internet, el 24\% definitivamente si lo recomendara y con un $16 \%$ está indeciso en recomendar.

Ante estos resultados se infiere que las personas no tienen aún esa confianza de realizar todas sus compras por internet, esto debido a que el salir de casa a realizar las compras es una manera de distraerse.

\begin{tabular}{|c|c|}
\hline COEFICIENTE DE & \\
CORRELACIÓN LINEAL & 0,66 \\
\hline
\end{tabular}




\section{Figura 10}

\section{Coeficiente de correlación lineal}

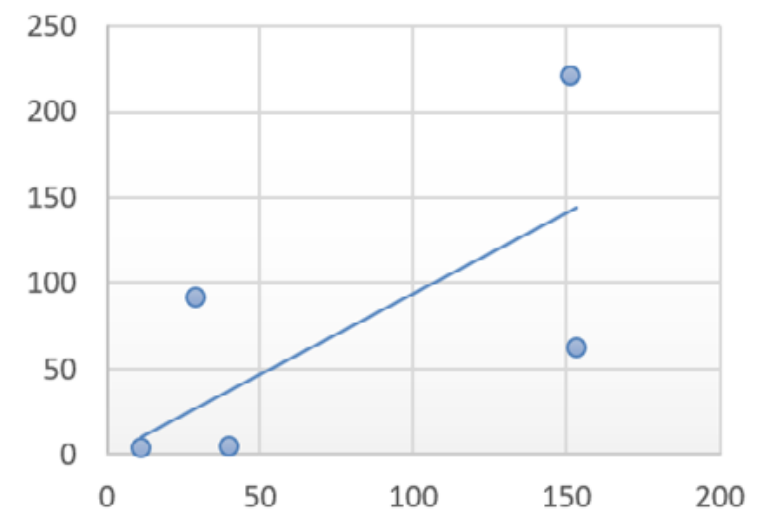

\section{Discusión}

Durante la investigación se identificó que la población cuenta con conocimientos previos acerca de las compras por medio de la web, se debe a los avances tecnológicos y a las necesidades crecientes que cada uno posee, puesto que se encuentran más involucrados en el mundo virtual. Así mismo Buff \& Zwanka (2020), mencionan que el confinamiento traerá cambios drásticos en el comportamiento del consumidor y señalan que las compras mediante internet serán practicadas durante y después de la pandemia.

La web 2.0 brinda un sinnúmero de redes sociales, de tal manera se pudo identificar que las personas utilizan con más frecuencia la red social Facebook la cual que fue utilizada para realizar las compras que la pandemia forzó a que las realice mediante la web.

En la encuesta también se pudo identificar como las medidas de confinamiento ocasionadas por el Covid 19 impactan en la conducta del consumidor, todo esto respecto a las prioridades del consumidor, de acuerdo con sus necesidades es así como se puede citar el modelo de necesidades de Maslow y el modelo psicológico social de Veblen. Maslow establece que el ser humano debe satisfacer sus necesidades básicas y después las necesidades avanzadas fisiológicas, seguridad, partencia, estima y autorrealización. El modelo Veblen considera al hombre como un animal social adaptado a normas culturales, sus conductas y deseos alcanzar.
En cuanto al coeficiente de correlación lineal de Pearson, se pudo cuantificar el grado de variación entre las dos variables con un 0,66 , siendo una correlación positiva, debido a su posicionamiento en un rango aceptable entre 0 y 1.

\section{Conclusiones}

En conclusión la pandemia del COVID 19, comprometió a que los consumidores busquen la manera de realizar las compras necesarias para su subsistencia y así satisfacer sus necesidades, es así como los consumidores están de acuerdo en que la pandemia forzó a que sus compras lo realicen mediante la web, ante este acto realizado durante el confinamiento el consumidor probablemente recomiende este método de compra, esto debido a que mediante el coeficiente de correlación lineal muestra una correlación estadística positiva, aludiendo que la conducta del consumidor cada vez es más tecnológica.

Para concluir con la investigación, la conducta del consumidor se ha visto en constantes cambios, una de ellas ante la pandemia ha sido realizar las compras desde casa, generando a esta actividad como muy cómoda. Ante estas experiencias realizadas por parte de los consumidores durante el confinamiento, ahora lo ven a las compras por la web como una actividad de confianza, lo que genera a que esta actividad sea recomendada con un $57 \%$.

\section{Referencias bibliográficas}

Alon, I., Farrell, M., \& Li, S. (2020). Regime type and COVID-19 response. FIIB Business Review, Online first, 1-9. Obtenido de https://journals.sagepub.com/ doi/10.1177/2319714520928884

Angus, A. (2020). How Is COVID-19 Affecting the top 10 global consumer trends 2020. Euromonitor Internacional network and coverage, 28.

Asesores Empresariales. (2020). El gran consumo ante el Covid. España: Pwc.

Buff, C., \& Zwanka, R. J. (2020). Journal 
of International Consumer Marketing. Obtenido de COVID-19 Generation: A Conceptual Framework of the Consumer Behavioral Shifts to Be Caused by the COVID-19 Pandemic: https://bit. $1 \mathrm{y} / 33 \mathrm{gbx} 6 \mathrm{v}$

Casco, R. (2020). Efectos de la pandemia de COVID-19 en el comportamiento del consumidor. Innovare Revista de Ciencia y Tecnología, 5 .

Donders, F., Lonnée-Hoffmann, R., Tsiakalos, A., Mendling, W., Martinez de Oliveira, J., Judlin, P., Xue, F., Donders, G. e Isidog el mieCovid-Guideline Workgroup (2020). Recomendaciones de ISIDOG sobre COVID-19 y el embarazo. Diagnostics (Basilea, Suiza) , 10 (4), 243. https://doi. org/10.3390/diagnostics10040243

Edelkoort, L., \& Rodi, N. (12 de Enero de 2020). World Global Style Network. Obtenido de https://www.ciceg.org/pdf/COVID19.pdf

Erazo, T. (2020). Cambio en el Gasto del consumidor. Quito: Universidad Internacional del Ecuador.

Felsenthal, M. (2020). La COVID-19 (coronavirus) hunde a la economía mundial en la peor recesión desde la Segunda Guerra Mundial. Washington: Banco Mundial.

Freire-Luisa, K. M., \& Mancheno-Saá, M. J. (2020). Covid 19 entre muerte y recesión económica. Revista Científica FIPCAEC (Fomento de la investigación y publicación en Ciencias Administrativas, Económicas y Contables). ISSN: 2588-090X. Polo de Capacitación, Investigación y Publicación (POCAIP), 5(5), 280-320Gemelli. (2020). Post-COVID-19 global health strategies: the need for an interdisciplinary approach. Aging clinical and experimental research, 32(8), 1613-1620. Obtenido de https://doi. org/10.1007/s40520-020-01616-x

Gemelli Against COVID-19 Post-Acute Care Study Group (2020). Post-COVID-19 global health strategies: the need for an interdisciplinary approach. Aging clinical and experimental research, 32(8), 16131620. https://doi.org/10.1007/s40520-02001616-x

Haro, A. (2020). Caracterización epidemiológica de Covid-19 en Ecuador. InterAmerican Journal of Medicine and Health, 1-7. Obtenido de https://bit.ly/2XfSaqj

IHME COVID-19 Forecasting Team (2021). Modeling COVID-19 scenarios for the United States. Nature medicine, 27(1), 94-105. https://doi.org/10.1038/s41591020-1132-9

Kirk, C., \& Rifkin, L. (2020). I'll trade you diamonds for toilet paper: Consumer reacting, coping and adapting behaviors in the COVID-19pandemic. Journal of Business Research, 117. Obtenido dehttps:// www.sciencedirect.com/science/article/ abs/pii/S0148296320303271?via\%3Dihub

Laato, S., Najmul, A., \& Nazrul , M. (2020). What drivesunverified information sharing and cuberchondria during COVID-19 pandemic? Europa: European Journal of Information Services. Obtenido de https:// www.tandfonline.com/doi/full/10.1080/09 60085X.2020.1770632

León, A., \& Mancheno, M. J. (2017). Componentes del capital intelectual un enfoque hacia la innovación de las organizaciones. Revista Publicando, 4(12 (2)), 302-314.

Li, D., \& Atkinson, L. (2020). The role of psychological ownership in consumer happiness.Journal of ConsumerMarketing, ahead-of-print (ahead-of-print).

Llamuca-Pérez, S. L., Mancheno-Saá, M. J., \& Chaulisa-Chaluisa, S. (2019). E-banking, una necesidad de virtualización en el sector financiero ecuatoriano. Revista Científica FIPCAEC (Fomento de la investigación y publicación en Ciencias Administrativas, Económicas y Contables). ISSN: 2588- 
090X. Polo de Capacitación, Investigación y Publicación (POCAIP), 4(4), 578-594.

López, M. (2020). Los efectos del Covid-19 en el consumidor. México: Forbes Staff.

Mancheno, M. J., Salinas, J. M. G., Miranda, R. F. V., \& Yugcha, J. D. P. H. (2018). Caracterización de la logística comercial y su evolución. Revista Publicando, 5(15 (2)), 817-833.

Mehta, S., Saxena, T., \& Purohit, N. (2020). The New Consumer Behavior Paradigm amid COVID-19. Permanent or Transient, 22. Obtenido de https://journals.sagepub.com/ doi/10.1177/0972063420940834

Muso Guagchinga, E. F. (2020). Merchandising: un factor invisible en la industria turística.

Organización Mundial de la Salud. (2020). La Covid 19 y su origen. Estados Unidos.

Paredes, E., \& Velasco, M. (2015). Comportamiento del Consumidor. Unipamplona, 70.

Pumasunco, L. (2020). Tendencias y hábitos del consumidor 2020 y su impacto por Covid-19. Perú: Asociación de Exportadores.

Saá, M. J. M. (2016). Consideraciones sobre el Marketing Ético. Revista Publicando, 3(9), 509-519.

Saá, M. J. M., \& Miranda, R. F. V. (2016). Habilidades directivas y el desarrollo empresarial en la industria de calzado a través de la modelización. Revista publicando, 3(9), 620-637

Sánchez, D. (2015). Comportamineto del consumidor en la búsqueda de información de precios on-line. Universidad Autónoma de Madrid, 254.

Sheth, J. (2020). Impact of COVID-19 on consumer behavior: Will the old habits return or die? Journal of Business
Research. Obtenido de https://www. sciencedirect.com/science/article/abs/pii/ S0148296320303647?via\%3Dihub

Shi, Y., Wang, G., Cai, X.-p., Deng, J.-w., Zheng, L., Zhu, H.-h., . . Chen, Z. (2020). An overview of COVID-19. J Zhejiang Univ Sci B, 21 (5): 343-360. Obtenido de https://www.ncbi.nlm.nih.gov/pmc/ articles/PMC7205601/

Verzaro, R. y Nishida, S. (2020). El cirujano y la pandemia de COVID-19. Revista internacional de cirugía (LondresInglaterra),78,160-161. https://doi. org/10.1016/j.ijsu.2020.05.001

Wang, E., An, N., Gao, Z., Kiprop, E., \& Geng, X. (2020). Consumer food stockpiling behavior and willingness to pay for food reserves in COVID-19. Food Security. Obtenido de https://link.springer.com/ article/10.1007/s12571-020-01092-1 